\title{
Mathematics, Education, and Culture: A Contemporary Moral Imperative
}

\author{
Bill Barton
}

\begin{abstract}
In 1984 Ubiratan D'Ambrosio gave a plenary address at ICME-5 in Adelaide that set a new direction for a major research effort in socio-cultural issues in mathematics education. His recent work uses the metaphor of mathematics as a "dorsal spine" on which monsters, not beautiful creatures, are often built. What must we do, what action must we take, to prevent ourselves from building monsters with mathematics and in mathematics education? This paper argues that theoretical approaches drawing on ecological concepts can lead us to understand the interconnectedness of teaching and scholarship with culture and society. I postulate three principles for action that may help guide moral behaviour within our discipline.
\end{abstract}

\section{Introduction}

I am thinking back to 1984 , when I was a secondary mathematics teacher in New Zealand, and I attended my first ICME conference in Adelaide. The very first session I attended was Ubiratan D'Ambrosio's talk (D'Ambrosio, 1985). I remember being completely blown away by this. Here was Ubiratan D'Ambrosio bringing to my very small world in New Zealand a vision of a caring world society in mathematics education. And that changed my life, so it is a very great honour to be invited to come here at the end of my career and be able to present some thoughts about where that agenda has gone.

First, let us remember the pleasure within mathematics. Remember that this beauty is accessible to all, and exists even in the most elementary mathematics. An example is the visceral pleasure of a visual proof of a mathematical idea.

And there can be pleasure in all the mathematics of any curriculum. My personal favourite topic to teach was trigonometric equalities because I could talk about how the equation of the sum of sines helps us to understand the common knowledge of surfers that big ways come in threes, or that every seventh wave is a big one. Waves

\footnotetext{
B. Barton $(\bowtie)$

University of Auckland, Auckland, New Zealand

e-mail: b.barton@auckland.ac.nz

(C) The Author(s) 2017

G. Kaiser (ed.), Proceedings of the 13th International Congress on Mathematical

Education, ICME-13 Monographs, DOI 10.1007/978-3-319-62597-3_3
} 
arriving on surf beaches come from more than one storm, and if we add two similar sine functions we get a curve with three peaks.

Everyone has their own examples-ICMI's Klein Project is a multilingual collection of contemporary mathematics written for teachers.

It would be nice if the pleasure that we get from mathematics imbued the whole of mathematics education, but we know it does not. Why not? How do we manage to take the pleasure out of mathematics? This question underlies all that follows.

Let me now return to Ubiratan D'Ambrosio. It is an honour to be following up Ubiratan D'Ambrosio's thinking, so let me briefly, and with a broad brush-stroke, go over what he was on about.

He questioned inequity within mathematics education in a very fundamental way, and gave us some models for working towards creating a fairer world through a mathematics education that really paid attention to social and cultural issues. Many, many people have worked very strongly in this area, and I do not intend to give a summary of the comprehensive work that has been done.

In more recent years, Ubiratan D'Ambrosio started to talk about mathematics as a dorsal spine. I want to highlight this metaphor because it is a very nice way of thinking about what has happened.

He sees mathematics as the dorsal spine of civilization, the basis of science and technology (D'Ambrosio, 2007, 2015). The trouble is that you may have a spine and skeleton on which an animal may be built, but that animal sometimes turns into a monster rather than a beautiful creature. This has happened within mathematics, and, I would argue, within mathematics education.

D'Ambrosio suggests that our essential goals are responsible creativity and ethical citizenship. What he did was highlight the role of mathematics and mathematics education in achieving both of those goals. In other words, he was pointing us to the wider reasons for our work as mathematicians and mathematics educators.

But how? How do we do this? What is it I am supposed to do to engender responsible creativity and ethical citizenship? When I walk up the steps and go into my office, what actions will I take?

I can presumably do some things in the way I behave, but how do I help to engender appropriate actions in the students that I teach? How are we to build a beautiful creature and not a monster. I think that D'Ambrosio's essential message is that we should reinstate cultural processes within mathematics education in order to build beautiful creatures. I wish to think about what other things we might do.

To develop a basis for making possible actions more explicit I would like to invoke ecological systems theory, which was developed in the context of child development by Urie Bronfenbrenner in 1979, a couple of years after D'Ambrosio introduced the ethnomathematical approach. The two theories have some overlapping principles (Bronfenbrenner, 1992). 


\section{Theoretical Frame-Ecological Systems}

Ecological systems theory is the idea of thinking about development within a wider environment. Ecology is the study of living things, hence the ecology of mathematics, or mathematics education, is thinking about these fields as living entities in a large environment. That's what I want to do, and you can see the links with what D'Ambrosio was doing. Bronfenbrenner identified five environmental systems to help his analysis. The five systems are not intended to be discrete.

The first is the microsystem. This includes the institutions and groups most directly involved. For mathematics, we might consider a university mathematics department; for mathematics education we could think of the group of mathematics teachers in a school. If we think only at this level, the actions we might take to create a more equitable or humane mathematics education are reasonably clear: schools and universities should be equally resourced-and maintained at those levels. Seems simple enough, but it does not happen. A deeper analysis is required.

The mesosystem is the interactions within the microsystem and between it and the living object. For example a lecture is part of the mathematics mesosystem, a school mathematics lesson is part of the mathematics education mesosystem. This is the context in which it might be useful to ask, for example, how interactions differ for girls and boys, men and women.

The exosystem is a slightly wider social setting. For example, some parts of mathematics develop and grow within the financial world. What influence does that have on the kind of mathematics that develops. In schools, mathematics learning takes place in an environment that includes other subjects. In what way does the fact that children go from a mathematics class to, say, a physical education lesson, affect how they learn mathematics? We can see that relevant questions concerning the exosystem would be whether mathematics represents the interests of one section of society over another, or how mathematics education takes on different characteristics in all girls schools compared with all boys schools.

The macrosystem lifts us to the cultural context and to regional or national features such as socioeconomic status and ethnicity. In what way, for example, does the mathematics developed in, say, a Chinese university reflect the fact that it is in the Republic of China or that particular part of China and is spoken and written in Chinese? In mathematics education, we might ask how the socioeconomic status of a community relates to the kinds of mathematics experiences each child receives.

The chronosystem is the one in which I have developed a personal interest, and represents the extension to D'Ambrosio's work that I would like to focus upon. This refers to the rather larger environment: the events, transitions, and historical circumstances within which mathematics and mathematics education sit. For example we know that not only did Archimedes and other classical mathematicians work on the development of war machines, but still, today, much mathematics research is funded by Departments of Defense and contributes to armament production. Also it is secret. We can immediately think of some of the monsters built on the dorsal spine of mathematics. 
Another question arising from considering the chronosystem would be what difference does it make to the endeavour of mathematics that we are now in a time of global warming? What role does mathematics and mathematics education have in the weather crises that strike communities?

So we come back to the essential question. What sorts of things should we be doing in our mathematics education classrooms to address the way we respond to the environments in which we live and build things of beauty rather than monsters?

Bronfenbrenner's theory has expanded the research field of the sociology of mathematics education and heightened the imperative for ethnomathematical understanding. But we still do not have an action plan for helping students to achieve responsible creativity and ethical citizenship.

Ecological systems theory is related to other ecological concepts. Ecology has come out of its biological environment. Ecological humanity is a field that seeks to bridge the divide between science and the humanities (Rose \& Robin, 2004). It assumes that the organic and inorganic worlds are a single linked system. In order to make appropriate responses to issues that arise in all fields, we need to visualise ourselves within this whole system. For example, justice and education are part of a larger environment in which there is more than one "way of knowing", resulting in a diversity of knowledge.

If we think about ourselves living in one system, not separated from each other or from other aspects of our world, then the links between ourselves, each other, and our world define our existence. Furthermore these links are more than the "laws" of our existence, but they also become a guide for our behaviour. Amongst other effects, the links start to guide our behaviour in moral ways.

This leads to what I regard as the most important statement in this paper: the extent to which we free mathematics and mathematics education from society and culture is the extent to which we are absolving ourselves from responsibility to others and to our world. It frees us from social and cultural responsibility. Ultimately, this makes us amoral.

In other words, when we behave as if mathematics is culture free (whether we believe it or not), then we are saying that we are not responsible for inequality and discrimination, cultural or environmental degradation, damaging technology, or destructive social institutions. And we are responsible for these things. We all are.

A further theoretical idea linked to those I have mentioned is deep ecology, as developed by the Norwegian philosopher Arne Naess (1973), who argues that the way we approach environmental management is anthropocentric - focussing on its effect on humans. This is an error because our environment is not only more complex than we imagine, it is more complex than we are able to imagine. There will always be things about our environment that we cannot imagine. We are fundamentally incapable of grasping the enormity and interconnectedness of ecology. I argue that this is also true of mathematics and mathematics education.

The point I take from all this is that we are part of a global morality. Thus I should not just be thinking about whether I am being equitable to the students in my class, but I have to think about whether the way that I am conducting myself contributes to any wider inequities. 
So what does accepting that I live in a global environment mean for what I must now do? Out of this theoretical milieu, I distil three principles for us to use in carrying forward D'Ambrosio's agenda in both mathematics and mathematics education. I am beginning to try to act on these.

The Perspective Principle is the idea that we need to be aware of other ways of understanding. There always will be other ways of understanding, and some of them I will not be able to even imagine. I must constantly be aware of that and thinking about what that means.

The Reflexive Principle is the idea that we should do unto others as we would have them do unto us. This is not just personal: I must do to you as I would like you to do to me, but also, for example, mathematics and mathematicians must do to art and artists as they would like to be treated. Or schools must do to financial institutions as they would like financial institutions to respond to them. New Zealand must treat Germany as it would have Germany treat it. The Reflexive Principle must occur at all levels.

The Pleasure Principle is the idea that we should act so as to increase pleasure. Pleasure as a motivation is underneath everything. It is where we are headed, bringing pleasure on a global scale is really what we are about. We do spend a lot of time making mathematics pleasurable for the children in our classes, but do the systems that we support bring pleasure in general to the society in which we live?

\section{Examples}

I will now give some examples, some of which will relate to more than one principle. The examples will come from mathematics itself as a discipline and from mathematics education.

Mathematics is, par excellence, an example of the Perspective Principle. It embodies this principle in how it works - much of the mathematics of today could not have been imagined even two hundred years ago, it required shifts in conceptualisations of basic mathematical ideas. The very concept of a number has changed many times over mathematical history. This reminds us, of course, that today we cannot imagine aspects of the mathematics of the future. This has serious implications for university level mathematics education.

But the principle works at another level. How do people outside the field see mathematics? Do we have a good understanding of other ways of seeing our subject. This is critical for us as educators since many of our students come from other fields and are studying mathematics for its relationship to those fields. We are the poorer for not understanding their perspectives properly.

The consequences of developing any particular mathematical idea are also more complex than we can imagine. This highlights the responsibility for might happen in society as a result of a mathematical idea. What responsibility does a mathematician, or mathematicians as a group, have when their mathematics gets misused, or deliberately used for destructive ends? 
For example, where does responsibility lie for the 2007/8 global financial crisis? The argument concerning the role of mathematical models continues to rage. This implicates financial mathematicians, and indeed, the responses of mathematicians were defensive: "the banks did not listen to us enough", "our models worked well throughout the crisis", "it was greed, not the models, that caused the crisis", or "everyone knows that risk cannot be $100 \%$ calculated".

However, as soon afterwards as 2009, the mathematicians Emanuel Derman and Paul Wilmott were moved to develop an ethical manifesto for inventors of financial models (Derman, 2011). They thereby acknowledged that those devising mathematics to be used in society do bear some responsibility for the uses to which it is put. Perhaps this is where the International Mathematical Union needs to take leadership, and I invite members of the IMU Executive to consider these questions, and to undertake some research on the relationship between what mathematicians are doing and the meso- and chronosystems within which they work.

My second example concerns the Reflexive Principle, and also focuses on mathematicians. Mathematicians, rightly, expect teachers to love or respect mathematics, the subject they teach, and appreciate the work of mathematicians. The Reflexive Principle would have mathematicians, in return, to love or respect mathematics education and appreciate those who work in that field. In my experience they do: mathematicians I know have a deep interest in teaching and enjoy their interaction with students. However there have been exceptions, which mainly occur because someone believes that knowing mathematics is all that is required to teach it.

So on a personal level, generally, the principle is met. On a systems level, I am not so sure. For example, in many universities $20-30 \%$ of students are failed. Every year we reduce our cohort of students by $20 \%$, much of it through labelling students as failures. Do we do that to ourselves? That would be interesting. Every year we could evaluate all the teaching staff and declare the least effective $20 \%$ as failures and sack them.

The third example is about mathematics education. Let us think about our application of the Pleasure Principle. I know that most mathematicians regularly indulge their love for the subject, pursue news, puzzles, opportunities to explore ideas, and have (interminable) mathematical discussions. Do teachers similarly continue to seek and find pleasure in mathematics? I believe that although many do, there are also many who do not — and I think that there are probably good reasons for that. Most of these teachers would love to nurture their love for mathematics, but they do not have the time, or space, or resources to do that. Their exo- and macro-systems are not constructed to allow it. We must ask ourselves, what is it about the environments in which we live and teach that so degrades the ability of teachers to maintain their love for the subject? Why is it so difficult - it should not be.

The Perspective Principle applied to mathematics education is the ethnomathematical agenda. Many people are doing great work in this area, and I acknowledge their efforts. The basic idea has been taken and has branched out into political, cultural, sociological, and many other directions (see, for example, Gerdes, 1994).

I will not comment further except to link the Perspective Principle to Ubiratan D'Ambrosio's statement that a universal educational approach is to allow all students to begin with the essential cultural processes, which he explains as techniques 
of doing, explaining, and knowing about our natural and social environment. This, he says, is where a full understanding of the nature of mathematics will start. That is, the social and cultural ways of knowing of the child must be the starting point of mathematics education. As teachers we have a responsibility to at least be aware of diverse ways of knowing and their possible presence in those we teach.

We also need to keep thinking about the Perspective Principle on a personal level. For example, at international mathematics education conferences there are very few simultaneous translations, or even multilingual slide presentations. ICME as an institution could being doing more to be multilingual in its communications, and more "language-friendly" in its conferences. The Klein Project is one model of how this could work, reaching out to the various language communities for help in preparing translations of key documents.

My next example is again about the Reflexive Principle, this time looking at the way in which it works on a cultural and social group level. Working from the assumption that we are all in this together, it can be the basis for thinking about, and acting upon, mathematics education for migrant, cultural, and social groups. We all have the same rights to a mathematics education of quality.

So, if you do not speak the language of the teacher or the classroom that does not mean that your human rights or educational rights are suspended. Offering fewer mathematical opportunities in any way because of language is unacceptable.

Another example is streaming or banding or organising classes on ranking. What does research say about this practice? There are no significant differences on student achievement for either higher, middle or lower ranked students, although some studies show slight gains for higher groups and losses for middle and lower groups (Sukhnandan \& Lee, 1998). Streaming or banding has a proven detrimental effect on the self-esteem and attitudes to mathematics of middle and lower groups. It also reinforces social grouping and accentuates socio-economic differences (Hallam \& Parsons, 2014). In a recent paper, Alexander Pais (2013) makes the point that if we say that mathematics is essential for effective citizenship that means that anyone who fails at mathematics cannot be an effective citizen. Everyone we determine does not meet the mark in mathematics is excluded from effective citizenship. That is what we are doing.

Another way of looking at streaming is to imagine that it took place in our lives. Imagine, for example, that who you are allowed to dine with and what foods are available to you is determined by your ability as a cook as measured in a single 1-hr cooking examination that everyone takes when they turn 21 years old. The results are made public and it defines your culinary future. This is what we do with mathematics if we implement streaming or grouping or banding.

I believe in a stronger statement, however. In my eyes, streaming is against human rights. It is very simple. Every charter of human rights includes articles that prevent inhuman or degrading treatment, articles that assert your right to be free from any sort of discrimination, and, in particular, articles that state that no-one will be denied the right to education. Yet streaming or banding or grouping does all those things. Perhaps we are all open to being prosecuted sometime in the future?

Finally, let us return to the Pleasure Principle. If our students do not like mathematics, or learning, then we are unlikely to be able to teach them very much. 
"Pleasure" in this sense is not a momentary good feeling, but includes things like the feeling you get when you persist at something and achieve it, when you face and overcome a challenge, become awakened to new ideas, or share in group achievement.

However, I fear that rather than creating opportunities for these sorts of experiences and the pleasures they generate, we sometimes (often?) create a monster on the "dorsal spine" of mathematics education. Here are two of them.

No mathematician I know would rather be doing something else-but we do not let our students do what mathematicians do. Most students go through their 1218 years of mathematics education without having many authentic mathematical experiences. It is all learning what is already known and practicing it. It is what I call the 14 year apprenticeship. Imagine if you were a carpenter or a musician and for your first fourteen years you never actually built anything or played a whole piece of music, but simply learned theory and practiced skills. There would not be many builders around, and our concert halls might be empty.

Where is playing with mathematics, exploring its wonders, and creating new mathematical ideas or objects? I do acknowledge that many teachers and researchers are working to improve our practice in this area.

The other monster that we create as mathematics educators that engenders fear amongst large proportions of our students is frequent high stakes testing. Again the research is interesting (see Amrein \& Berliner, 2003; Nichols \& Berliner, 2007). Achievement does go up - but only on the tests themselves and the gains do not transfer elsewhere. High stakes testing also has negative systems effects. It diminishes the curriculum; has negative effects on students, teachers and schools; and decreases critical thinking.

We also know that it causes fear and loathing, not just amongst our students, but amongst parents and the society in which we live. So if we complain about those who exhibit math phobia, we must remember that we create it. Our whole system is designed that way, and we are part of the system. As Pogo, Walt Kelly's cartoon character says: "We have met the enemy, and he is us."

Again, using the Reflexive Principle makes this clear. Imagine there was frequent high stakes testing for carpenters, landscape gardeners, or, heaven forbid, Ministers of Education.

It seems to me that ICMI can take some leadership responsibility in this area. I argue that it is time to be a strong political voice that makes clear the consequences of certain practices in mathematics education that are destructive to our wider ecological environment. Such a stance would need to be clearly based on our collective research and experience.

But we also have a personal responsibility to make ourselves aware of how what we do reinforces poor, discriminatory, or destructive practices. By doing nothing, or by staying quiet, we reinforce an immoral status quo. Each of us has a responsibility to act. This means: actively seek understanding of others, others' ideas, and our environment; remaining aware of our participation in the structures within which we work; creating opportunities to discuss these issues with our colleagues; and standing up, individually and collectively, when we perceive monstrous features, horns, and claws growing on the dorsal spine of mathematics and mathematics education. 


\section{References}

Amrein, A., \& Berliner, D. (2003). The effects of high stakes testing on student motivation and learning. Educational Leadership, 32-38.

Bronfenbrenner, U. (1992). Ecological systems theory. In R. Vasta (Ed.), Six theories of child development: Revised formulations and current issues (pp. 187-249). London: Jessica Kingsley Publishers.

D'Ambrosio, U. (1985). Socio-cultural bases for mathematics education. In M. Carss (Ed.), Proceedings of the Fifth International Congress on Mathematics Education (pp. 1-6). Boston, MA: Birkhäuser.

D'Ambrosio, U. (2007). The Role of Mathematics in Educational Systems. ZDM Mathematics Education, 39, 173-181. doi:10.1007/s11858-006-0012-1.

D'Ambrosio, U. (2015). From mathematics education and society to mathematics education and a sustainable civilisation: A threat, an appeal, and a proposal. Opening address, Mathematics Education \& Society conference, Portland, Oregon. https://www.youtube.com/watch?v= SsgYqt_N_Hg\&feature=youtu.be

Derman, E. (2011). In Models. Behaving. Badly. Why confusing illusion with reality can lead to disaster, on Wall Street and in life. New York: Free Press.

Gerdes, P. (1994). Reflections on ethnomathematics. For the Learning of Mathematics, 14(2), 19-22.

Hallam, S., \& Parsons, S. (2014). Streaming pupils by ability in primary school widens the attainment gap. Presentation at the British Society for Research in Learning Mathematics Conference in 2014.

Naess, A. (1973). The Shallow and the deep, long-range ecology movement. Inquiry, 16, 95-100.

Nichols, S., \& Berliner, D. (2007). Collateral damage: how high-stakes testing corrupts america's schools. Cambridge: Harvard Education Press.

Pais, A. (2013). A critical approach to equity. In B. Greer \& O. Skovsmose (Eds.), Opening the cage: Critique and politics of mathematics education (pp. 49-92). Rotterdam: Sense.

Rose D., \& Robin, L. (2004) The ecological humanities in action: An invitation. Australian Humanities Review, 31, 2.

Sukhnandan, L., \& Lee, B. (1998). Streaming, setting, and grouping by ability: A review of the literature. UK: National Foundation for Educational Research.

Open Access Except where otherwise noted, this chapter is licensed under a Creative Commons Attribution 4.0 International License. To view a copy of this license, visit http://creativecommons. org/licenses/by/4.0/.

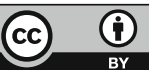

